\title{
DETECTION OF LAND USE AND LAND COVER CHANGES IN DIRAB REGION OF SAUDI ARABIA USING REMOTELY SENSED IMAGERIES
}

\author{
${ }^{1}$ Madugundu, R., ${ }^{1,2}$ K.A. Al-Gaadi, ${ }^{1}$ V.C. Patil and ${ }^{1}$ E. Tola \\ ${ }^{1}$ Precision Agriculture Research Chair, \\ ${ }^{2}$ Department of Agricultural Engineering, \\ College of Food and Agriculture Sciences, King Saud University, Riyadh, Saudi Arabia
}

Received 2013-12-22; Revised 2014-01-26; Accepted 2014-01-30

\begin{abstract}
Knowledge of Land Use and Land Cover (LULC) changes is important for many planning and management activities. It is thought to be an essential element for modeling and understanding the major land forms, especially in arid regions like Saudi Arabia. This study investigates the LULC changes in Dirab region of Saudi Arabia between 1980 and 2010, using Landsat TM/ETM+images. After the geometric correction and radiometric normalization, multi-temporal image data sets were spectrally enhanced separately using Principal Component Analysis (PCA) and Tasseled Cap Transformation (TCT). Each image was then separately subjected to supervised classification and processed to identify and quantify LULC changes (vegetation, barren land and built-up area). Post Classification Comparison (PCC) method was adopted for LULC change detection. Change trajectories ("from-to" classes) and accuracy assessments were made by comparing the detected land use change layers with medium/high resolution images of Google Earth data base. The TCT enhanced procedure gave better identification of the changed areas than PCA based method. The overall accuracy of PCA based change detection was $64.58,62.68$ and $62.12 \%$ for 1980 1990, 1990-2000 and 2000-2010 images, respectively. However, the TCT based change detection resulted in higher accuracy of $77.78,75.62$ and $77.92 \%$ for $1980-1990,1990-2000$ and $2009-2010$, respectively. The results suggested that significant land use changes occurred in Dirab area from 1980 to 2010, which may be related to rapid development of agriculture between 1980 and 2000 and economic development and urban expansion between 2000 and 2010. It was further noted that most changes occurred in cropland areas due to urban encroachment.
\end{abstract}

Keywords: Principal Component Analysis, Tasseled Cap Transformation, Temporal Changes, Post Classification Comparison, Saudi Arabia

\section{INTRODUCTION}

Information on land use/land cover change is essential for the selection, planning and implementation of land management schemes to meet the increasing demands for basic human needs and welfare (Reddy and Gebreselassie, 2011). Remotely sensed change detection based on multitemporal, multispectral and multisensor imagery provides this information (Singh, 1989; Othman et al., 2013). LULC studies include, image enhancement, LULC classification and change detection. Principal Component Analysis (PCA) and Tasseled Cap Transformation (TCT) are more commonly used image enhancement methods (Lu et al., 2004). Principal Component Analysis (PCA) transforms a set of correlated image bands in to a new set of uncorrelated image bands that are ordered based on the amount of variance explained in the original data (Eastman and Fulk, 1993). PCA was used for LULC change studies from Landsat TM (Mather, 1999), SPOT (Carr and Matanawi, 1999), IKONOS (Bernardini et al.,

Corresponding Author: Madugundu, R., Precision Agriculture Research Chair, College of Food and Agriculture Sciences, King Saud University, Riyadh, Saudi Arabia 
2008) and hyperspectral (Licciardi et al., 2012) imagery. Tasseled Cap Transformation (TCT) is another method of enhancing spectral information of satellite data. TCT was first applied to Landsat MSS (Kauth and Thomas, 1976) and further extended to other sensors such as Landsat TM (Crist, 1985), ETM+ (Huang et al., 2002), IKONOS (Horne, 2003), MODIS (Lobser and Cohen, 2007) and CBERS 02B-China and Brazil Earth Resource Satellite (Sheng et al., 2011). In recent years, TCT has been widely used in LULC change detection (Dymond et al., 2002; Han et al., 2007; Liu and Liu, 2010). Supervised and unsupervised classification techniques are two widely used methods of classifying LULC (Lillesand and Kiefer, 2000). Out of several change detection procedures available Post Classification Comparison (PCC) is one of the most widely used methods (Lu et al., 2003). Change detection generally employs one of two basic methods: Pixel-topixel comparison and post-classification comparison (Jaiswal et al., 1999). The post classification method compares two or more separately classified images of different dates (Fung and Zhang, 1989). It is considered to be one of the most appropriate and commonly used methods for change detection (Jensen, 2005).

Several LULC change detection studies were reported (Daniel et al., 2002; Lu et al., 2004; Berberoglu and Akin, 2009; Tahir et al., 2013). However, such studies are limited in Saudi Arabia. Example of these studies includes the one conducted by Al-Washe and Bokhari (1993) who assessed the vegetation changes for urban planning in Al-Madina. Al-Rowili et al. (2003) assessed changes in the urban areas of Jeddah City between 1988 and 1998. Similar study was conducted by Bagour et al. (2006) to evaluate the extent of vegetation changes in north-eastern part of the Kingdom of Saudi Arabia due to the 1991 Gulf War. Agricultural land use changes through the period from 1988 to 2008 was monitored and assessed by Al-Harbi (2010). Also, AlGaadi et al. (2011) studied the NDVI based temporal land cover changes in Dirab region between 1990 and 2006. Another study was conducted by Hereher et al. (2012) to analyze land cover and topography of Hail region, between 1972 and 2000 .

Drastic developmental activities are undertaken in the past two decades in Dirab region of Saudi Arabia. As part of this development, structures like Golf club, Arab National Park, KSU research farm, ARABSAT Satellite earth station are being established along with the development of agricultural fields and date palm orchards. In order to assess the impact of these development activities, this study was carried out with the following objectives: (1) to assess Land Use and Land Cover (LULC) changes and their trajectories ("from-to" classes) of Dirab region from 1980 to 2010 and (2) to compare Principal Component Analysis (PCA) and Tasseled Cap Transformation (TCT) of enhanced Landsat TM/ETM+ images for LULC using Post Classification Comparison (PCC) technique.

\section{MATERIALS AND METHODS}

\subsection{Study Area}

The study was conducted for Dirab region, which is located about $50 \mathrm{~km}$ west of Riyadh and lies between $24^{\circ} 20^{\prime} 35^{\prime \prime}$ and $24^{\circ} 20^{\prime} 51^{\prime \prime} \mathrm{N}$ latitude and between $46^{\circ} 31^{\prime} 41^{\prime \prime}$ and $46^{\circ} 45^{\prime} 34^{\prime \prime}$ E longitude (Fig. 1). Dirab region experienced dry continental climate with hot summer and cold to moderate winters with a mean temperature of $35^{\circ} \mathrm{C}$. Geologically, Dirab region is covered with predominant sandstone and subordinate limestone from Mesozoic age. Sedimentary rock formation, which under laid Dirab region, is part of an extremely thick rock bed that dipped easterly into the Arabian shield. The water-bearing sand and limestone beds store substantial volume of water and constitute an important alluvial aquifer. Topographically, Dirab region is steeply undulating terrain dissected by valleys Lida and Al-Awast which are exploited mainly for their high agricultural potential. Wheat and alfalfa are the major crops grown in the region, using centre pivot irrigation system.

\subsection{Image Processing}

Geo-corrected cloud free Landsat TM and ETM+imageries were downloaded from USGS website (Table 1) and geo-referenced to the Universal Transverse Mercator (UTM) coordinate system with WGS1984 as spheroid and datum across the north zone of 39 using a reference image. In this study, Landsat image of 2000 (path: 166/row: 43) was considered as a reference image. A minimum of 25 evenly distributed Ground Control Points (GCPs) were selected from the images. Re-sampling was performed using nearest neighbor algorithm. The transformation had a RMS error of less than 0.5 pixels indicating that the image was accurate within one pixel. These images were radio-metrically (Top of Atmosphere) corrected by applying Radiative transfer model utilizing pre-launch calibration constants of TM and ETM+ (Chander and Markham, 2003). For the SLC-off images (i.e., 7th September 2010), the bad pixels were replaced by the nearest date of acquired image (23rd September 2010) through image mosaic with histogram equalization options. 


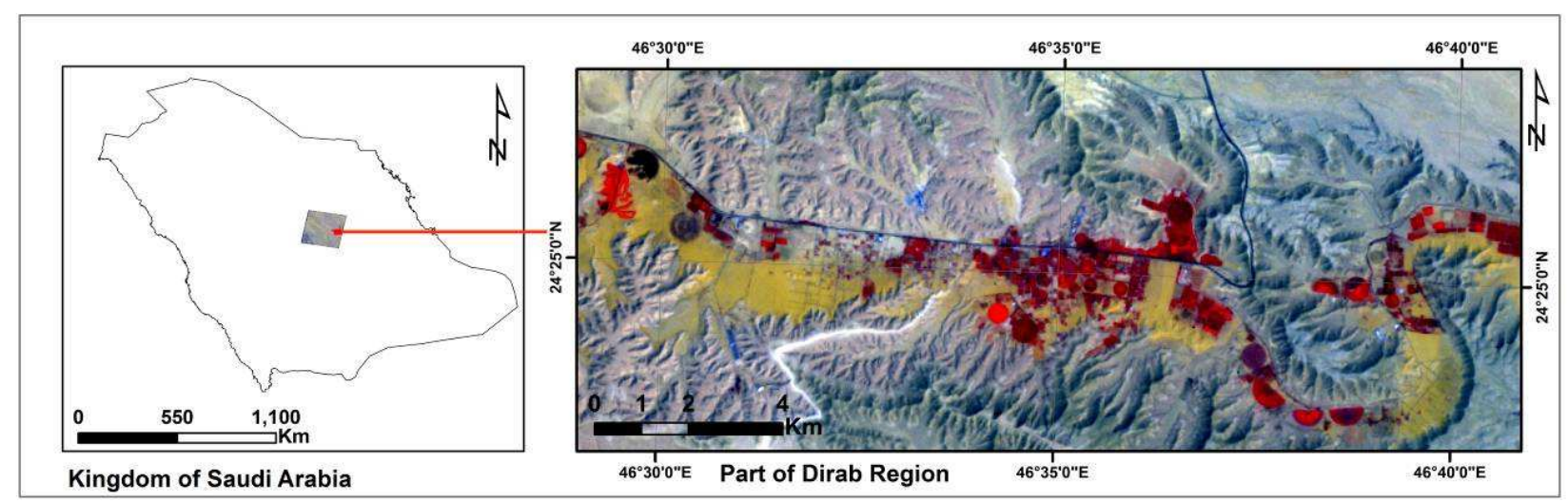

Fig. 1. Location map of dirab region (Study Area)

Table 1. List of remotely sensed data used for the study

\begin{tabular}{llll}
\hline S1. No & Sensor & Path/Row & Date of pass \\
\hline 1 & Landsat 4 & $166 / 43$ & $14 / 09 / 1980$ \\
2 & Landsat TM & $166 / 43$ & $07 / 09 / 1990$ \\
3 & Landsat ETM+ (SLC on) & $166 / 43$ & $02 / 09 / 2000$ \\
4 & Landsat ETM+ (SLC off) & $165 / 43$ & $07 / 09 / 2010$ \\
5 & Landsat ETM+ (SLC off) & $165 / 43$ & $23 / 09 / 2010$ \\
\hline
\end{tabular}

After geometric correction and radiometric normalization, multi-temporal image data sets were spectrally enhanced separately using PCA and TCT. Each image was then separately classified by adopting supervised classification method and processed to identify and quantify land use changes.

\subsection{Principal Component Analysis}

Top of Atmosphere (TOA) corrected Landsat images were subjected to PCA using multivariate algorithm (PCA of ERDAS Imagine software) to generate Eigen images (i.e., PCA outputs). In general, when PCA is applied to data embracing several spectral bands, it concentrates almost all of the information in the first two or three components. The other components generally contain only noise (Deng et al., 2008). In this study, a color composite of Eigen images generated from the first three principal components was used for classification and change detection.

\subsection{Tasseled Cap Transformation (TCT) Analysis}

In this study, the Tasseled Cap Transformation was carried out for TOA corrected Landsat satellite imagery by applying Huang et al. (2002) developed band-wise coefficients (Table 2) to Equation (1):

$$
\begin{aligned}
& \text { TCT }_{\mathrm{i}}=\left(\operatorname{coeff}_{1} \times \text { band }_{1}\right)+\left(\operatorname{coeff}_{2} \times \text { band }_{2}\right) \\
& +\left(\operatorname{coeff}_{3} \times \text { band }_{3}\right)+\left(\operatorname{coeff}_{4} \times \text { band }_{4}\right) \\
& +\left(\operatorname{coeff}_{5} \times \text { band }_{5}\right)+\left(\operatorname{coeff}_{6} \times \text { band }_{6}\right) \\
& +\left(\operatorname{coeff}_{7} \times \text { band }_{7}\right) \ldots .(1)
\end{aligned}
$$

where, $\mathrm{TCT}_{\mathrm{i}}$ is the calculated tasseled cap transformation index for brightness, greenness and wetness depending on the coefficients used.

The generated PCA and TCT ( 3 band) images were classified separately using supervised classification technique and processed to assess LULC and its trajectories.

\subsection{Change Detection}

Post Classification Comparison (PCC) method results in a residual image which represents the change resulting from the subtraction of differently dated images (time 2-time 1). The most widely used change detection algorithm is the PCC which detects changes between hand-labeled region classes (Currit, 2005; Petit et al., 2001). This technique provides detailed change trajectories between the two images. Moreover, the independent classification processes reduce the impact of multi-temporal effects due to atmosphere or sensor differences (Lu et al., 2004). The changed pixels extracted between the study period (i.e., between 1980 and 2010) were used to define (a) "from-to" land use/land cover class, (b) the area coverage and (c) their trajectories. To determine statistics of the area coverage, outliers were removed by applying $3 \times 3$ statistical filter with majority function and only the absolute pixels/classes were used as threshold values for change detection. 
Madugundu, R. et al. / American Journal of Environmental Science 10 (1): 8-18, 2014

Table 2. Coefficients of the "Tasseled Cap Transformation" of Landsat data

\begin{tabular}{lrrrrrr}
\hline Components & Band-1 & Band-2 & Band-3 & Band-4 & Band-5 & Band-7 \\
\hline Brightness (R) & 0.3561 & 0.3972 & 0.3904 & 0.6966 & 0.2286 & 0.1596 \\
Greenness (G) & -0.3344 & -0.3544 & -0.4556 & 0.6966 & -0.0242 & -0.2630 \\
Wetness (B) & 0.2626 & 0.2141 & 0.0926 & 0.0656 & -0.7629 & -0.5388 \\
\hline
\end{tabular}

Source: Huang et al. (2002)

Trajectories were determined using change matrix generated from the overlaid images.

\subsection{Accuracy Assessment}

Accuracy assessment including overall accuracy, producer's and user's accuracy was carried out and Kappa coefficient was determined (Berberoglu and Akin, 2009). The LULC changes were verified with medium/high spatial resolution images of Google Earth for the respective study period. Accuracy assessment modules of ERDAS imagine-2010 was used to determine the image classification accuracy. For the images with no ground validation data, the stratified random sampling method (Jensen, 2005) was used to generate 84 reference points for the whole study area. These reference points were generated according to the different strata and overlaid on the Google Earth image to check if the given class falls into the same spectra.

\section{RESULTS}

\subsection{Classification of Images}

The data sets pertaining to supervised classification of PCA and TCT enhanced Landsat images are depicted in Fig. 2 and 3, respectively and the area statistics are provided in Table 3 .

\subsection{PCA Images}

In the year 1980, the area under agriculture/vegetation was $6.34 \%$ of the area under study. Other classes such as current fallow and barren area covered 2.14 and $91.52 \%$ of the study area. However, there was no representation of built-up area. Over the period, the area under agriculture increased to 9.31 and $10.29 \%$ in the year 1990 and 2000 respectively, which decreased to $7.73 \%$ in the year 2010 . The built-up area, however, showed a gradually increasing trend with no built up area in 1980 to $0.67 \%$ in 1990 ; to $0.82 \%$ in 2000 and to $1.3 \%$ in 2010 .

\subsection{TCT Images}

Drastic change was observed in TCT analyzed wetness, brightness and greenness indexes during the study period (Fig. 4). There was increased brightness and decreased wetness and greenness witnessing the LULC changes in the study area.

TCA+supervised classified data showed a trajectory changes from vegetation and barren areas to built-up area during 1980-2010. In the year 1980, the area under agriculture/vegetation was occupied by $5.9 \%$ of the total area, which gradually increased to $9.01 \%$ in 1990 ; and to $9.81 \%$ in 2000 . But in the year 2010, it was declined to $7.66 \%$. Other classes such as current fallow and barren area covered $2.02 \%$ and $92.08 \%$ of the area in 1980. Current fallow area gradually increased through $3.38 \%$ (1990) to $4.05 \%$ (2000) and declined to $3.75 \%$ in 2010 . Barren land decreased to $86.72 \%$ in 1990 and to $85.02 \%$ in 2000 . But in the year 2010, the barren increased to $91.54 \%$. There was no representation of built-up area in 1980 which was gradually increased to $0.88 \%$ in 1990 ; to $1.12 \%$ in 2000 ; and to $1.56 \%$ in 2010 .

\subsection{Change Detection Analysis}

The results of change detection using Post Classification Comparison (PCC) of PCA and TCT images are shown in Fig. 5 and 6. The change detection and trajectory areas are given in Table 4. In case of PCA+PCC, about 2.97 and $0.67 \%$ of barren area was converted into vegetation/agriculture and built-up area, respectively between 1980 and 1990. Similar trend was observed between 1990 and 2000 with the expansion of agriculture/vegetation $(0.98 \%)$ and builtup area $(0.67 \%)$. However, between the years 2000 and 2010, agriculture/vegetation area declined and the barren area increased to $2.56 \%$. However, the expansion of built-up area $(0.48 \%)$ from barren area was observed between the years 2000 and 2010 (Table 4). In case of TCT+PCC, about $3.11 \%$ and $0.88 \%$ of barren area was converted as vegetation/agriculture and built-up area, respectively between 1980 and 1990 . Similar trend was observed between 1990 and 2000 with the expansion of agriculture/vegetation (0.80\%) and built-up area $(0.24 \%)$. On the contrary, agriculture/vegetation area became to barren $(2.15 \%)$ between the year 2000 and 2010 . However, between the years 2000 and 2010, the built-up area was expanded to $0.44 \%$, which was from barren area (Table 4 ). 
Madugundu, R. et al. / American Journal of Environmental Science 10 (1): 8-18, 2014

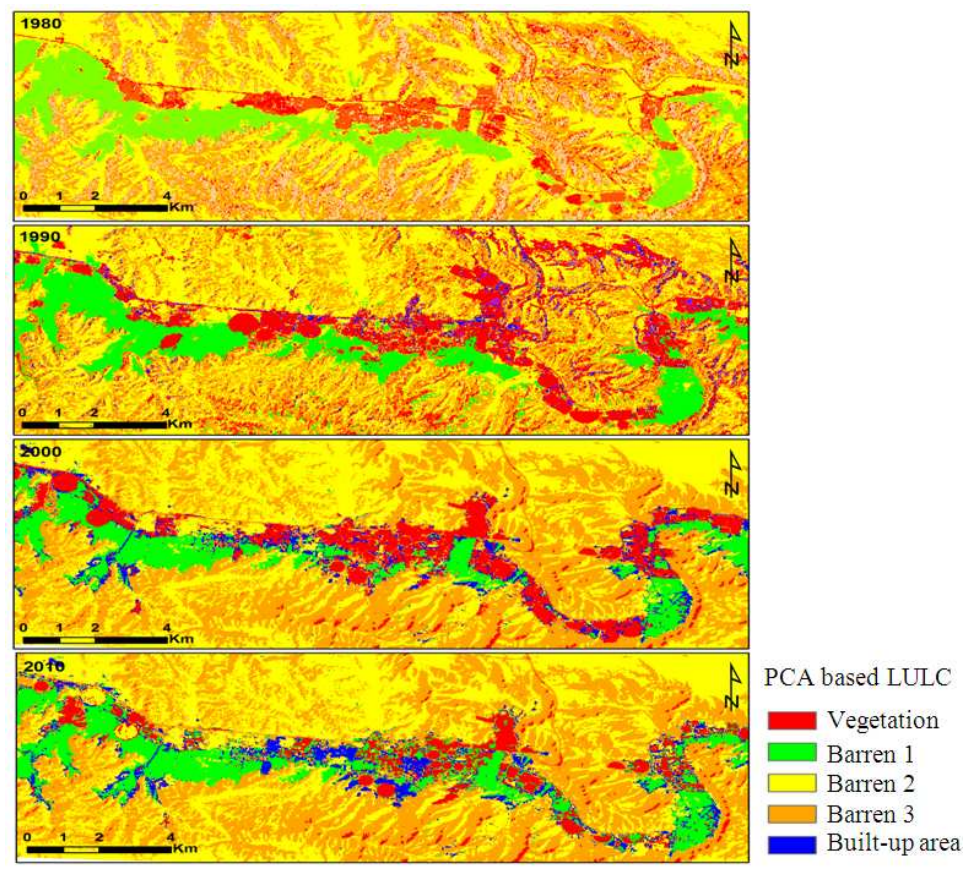

Fig. 2. PCA based classified (supervised) land use land cover map of Dirab region

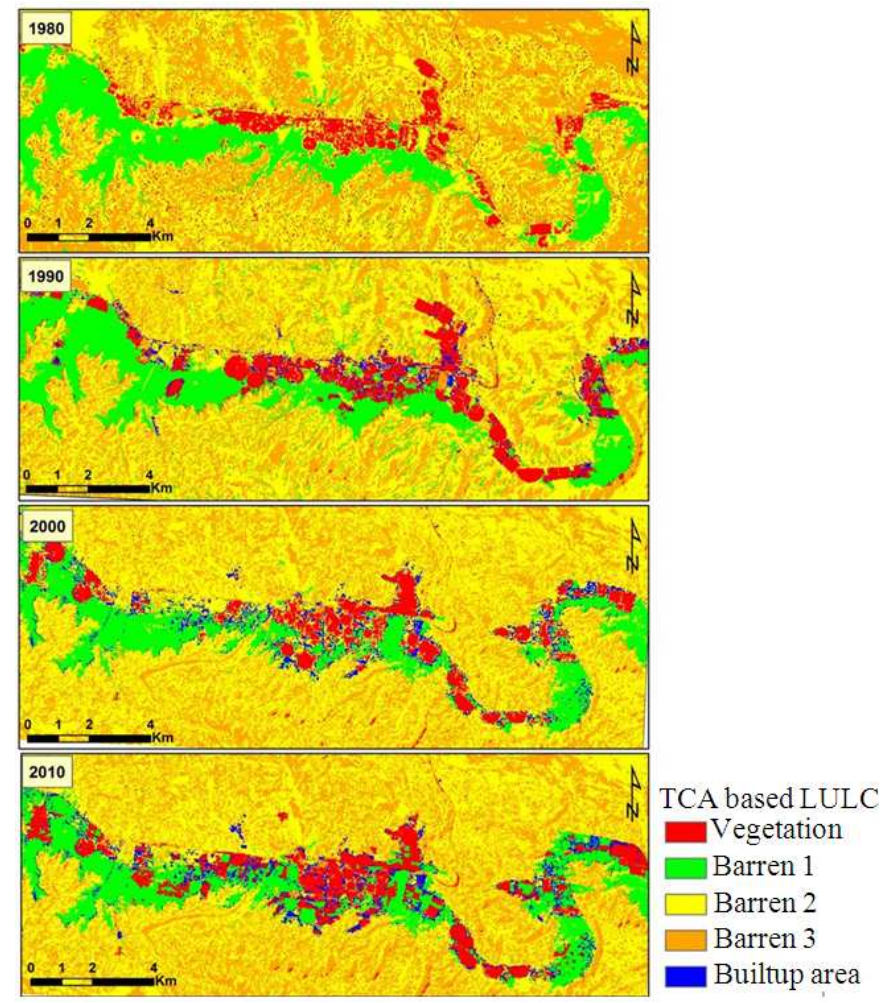

Fig. 3. TCA based classified (supervised) land use land cover map of Dirab region 
Madugundu, R. et al. / American Journal of Environmental Science 10 (1): 8-18, 2014

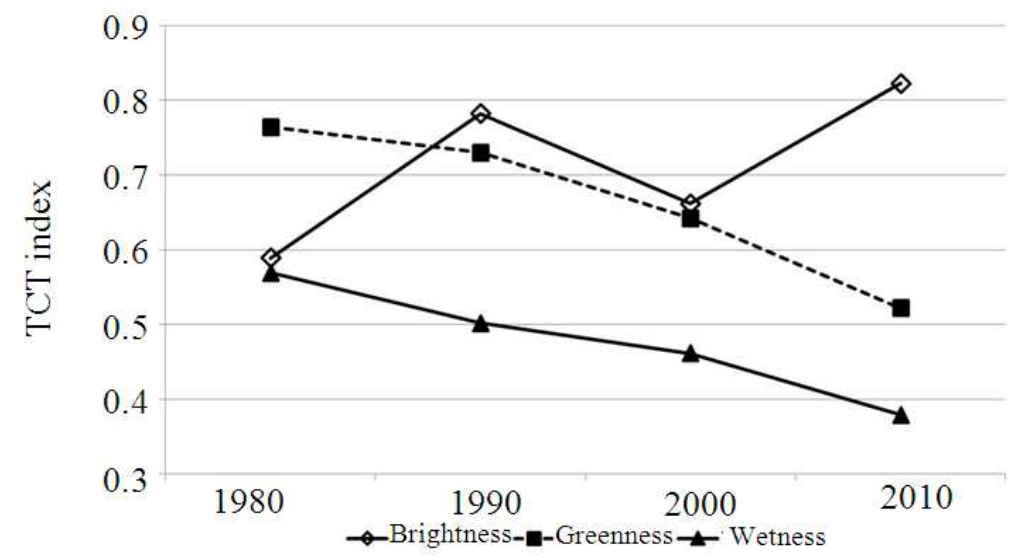

Fig. 4. Temporal variation in tasseled cap transformation index for brightness, greenness and wetness

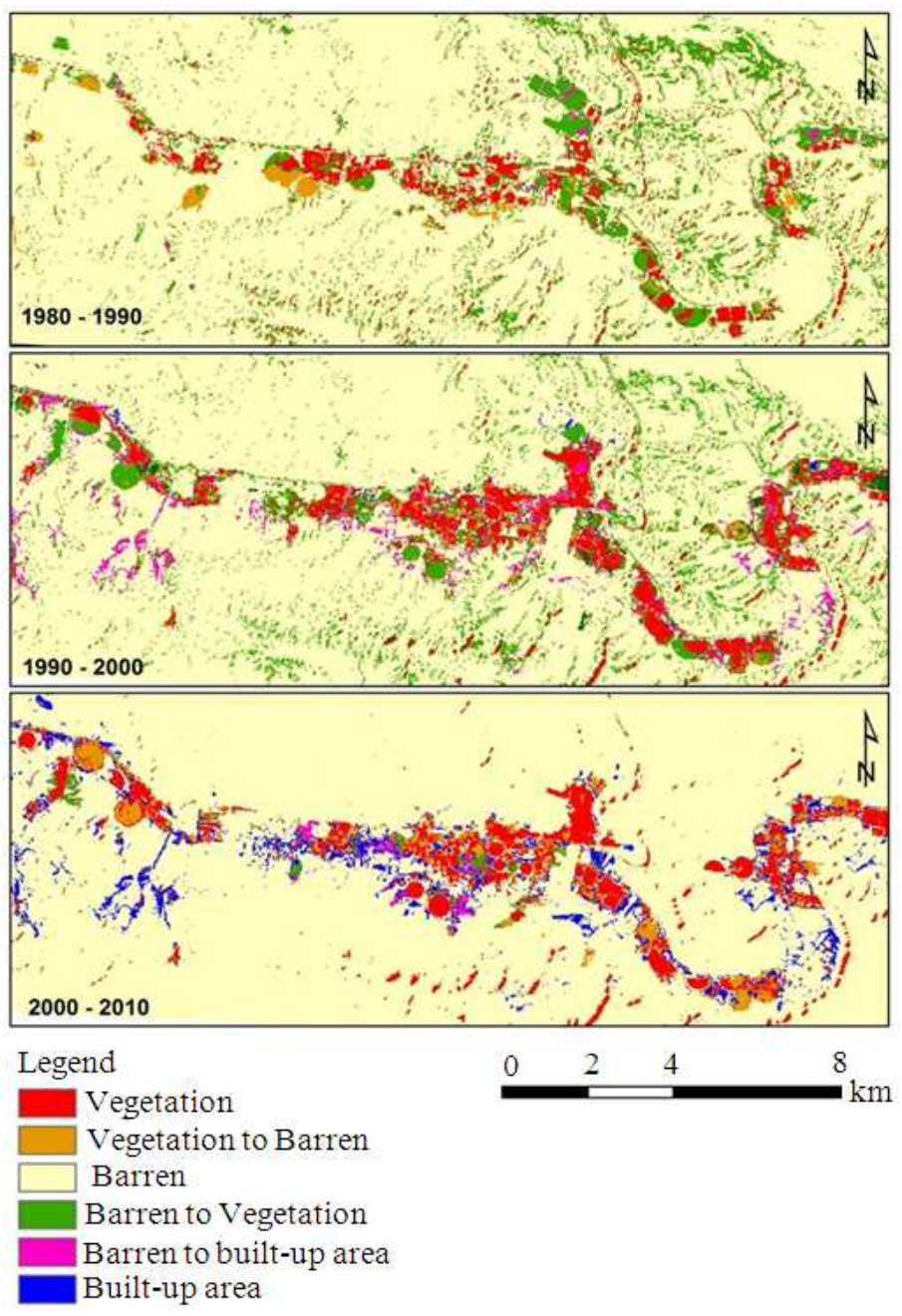

Fig. 5. PCA based trajectories of land use land cover changes during the study period in Dirab region 
Madugundu, R. et al. / American Journal of Environmental Science 10 (1): 8-18, 2014

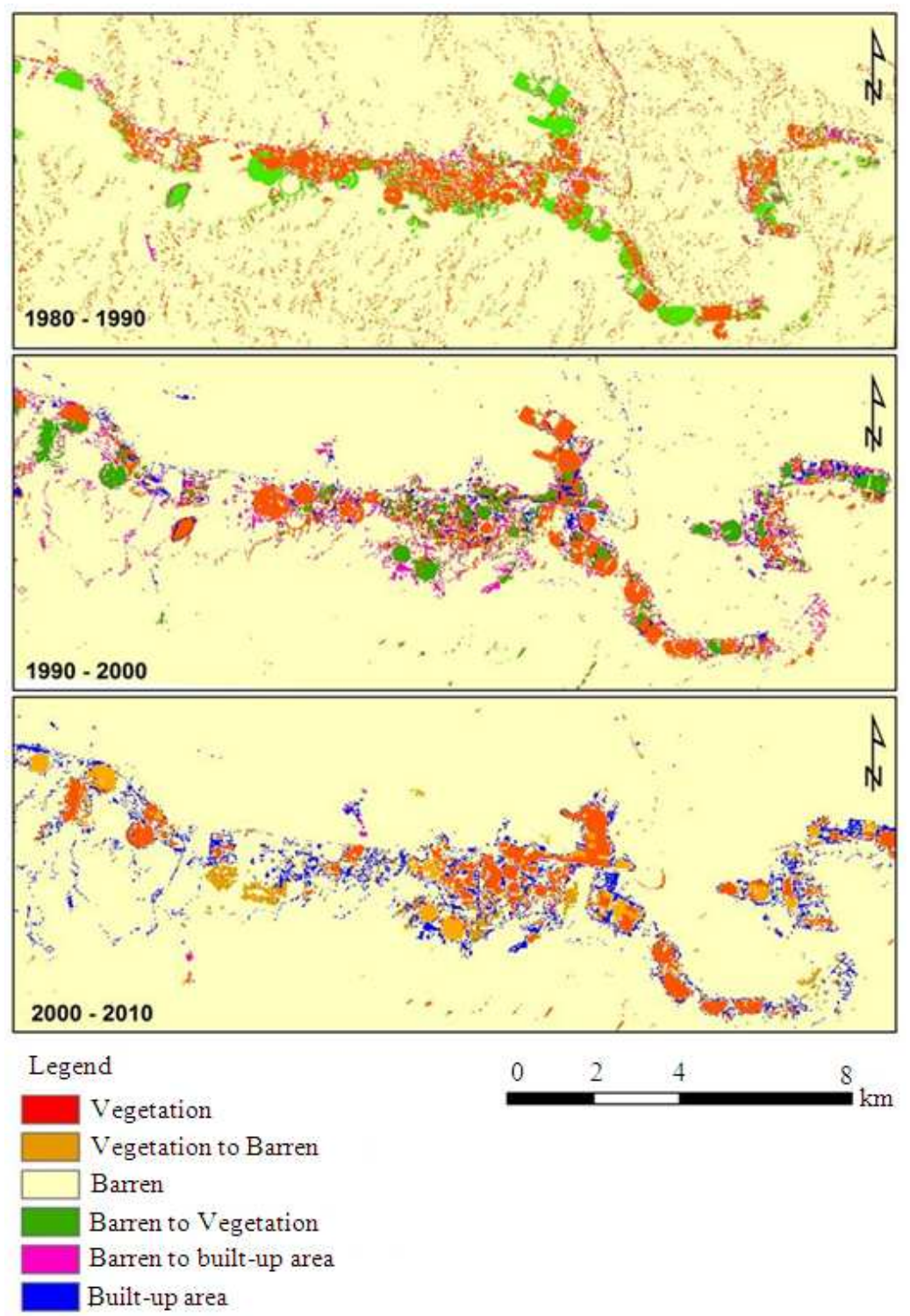

Fig. 6. TCA based trajectories of Land Use Lnd Cover Changes during the study period in Dirab region

Table 3. Land Use Land Cover area (\%), parts of Dirab region, Saudi Arabia

\begin{tabular}{|c|c|c|c|c|c|c|c|c|}
\hline \multirow[b]{2}{*}{ LULC } & \multicolumn{4}{|c|}{ Principle Component Analysis (PCA) } & \multicolumn{4}{|c|}{ Tassel Cap Transformation (TCT) } \\
\hline & 1980 & 1990 & 2000 & 2010 & 1980 & 1990 & 2000 & 2010 \\
\hline Agriculture/Vegetation & 6.3400 & 9.3100 & 10.2900 & 7.7300 & 5.9000 & 9.0100 & 9.8100 & $\overline{7.6600}$ \\
\hline Current Fallow & 2.1400 & 3.5400 & 4.2400 & 3.8600 & 2.0200 & 3.3800 & 4.0500 & 3.7400 \\
\hline Barren (plane area) 1 & 28.0600 & 23.0200 & 21.1900 & 23.6500 & 28.9600 & 23.7600 & 21.6700 & 23.8500 \\
\hline Barren (valley area) 2 & 27.8700 & 27.8700 & 27.8700 & 27.8700 & 29.0700 & 29.6300 & 28.2800 & 28.8300 \\
\hline Barren (valley area) 3 & 35.5900 & 35.5900 & 35.5900 & 35.5900 & 34.0500 & 33.3400 & 35.0700 & 34.3600 \\
\hline Built-up & 0.0000 & 0.6700 & 0.8200 & 1.3000 & 0.0000 & 0.8800 & 1.1200 & 1.5600 \\
\hline Kappa & 0.6667 & 0.6861 & 0.6519 & 0.6973 & 0.6978 & 0.7452 & 0.7555 & 0.7524 \\
\hline
\end{tabular}


Madugundu, R. et al. / American Journal of Environmental Science 10 (1): 8-18, 2014

Table 4. Confusion Matrix of LULC (\% of area) over the study period based on image enhancement and PCC techniques

\begin{tabular}{|c|c|c|c|c|c|c|c|}
\hline \multirow[b]{2}{*}{ Time 1} & \multirow{2}{*}{$\begin{array}{l}\text { Time } 2 \\
\text { LULC Class }\end{array}$} & \multicolumn{3}{|l|}{$\mathrm{PCA}+\mathrm{PCC}$} & \multicolumn{3}{|l|}{$\mathrm{TCT}+\mathrm{PCC}$} \\
\hline & & Agriculture & Barren & Built-up & Agriculture & Barren & Built-up \\
\hline \multirow{4}{*}{1980} & 1990 & & & & & & \\
\hline & Agriculture & 6.34 & - & - & 5.90 & - & - \\
\hline & Barren & 2.97 & 90.02 & 0.67 & 3.11 & 90.11 & - \\
\hline & $\begin{array}{l}\text { Built-up } \\
2000\end{array}$ & - & - & - & - & - & 0.88 \\
\hline \multirow[t]{3}{*}{1990} & Agriculture & 9.31 & - & - & 9.01 & - & - \\
\hline & Barren & 0.98 & 88.89 & 0.15 & 0.80 & 89.07 & 0.24 \\
\hline & $\begin{array}{l}\text { Built-up } \\
2010\end{array}$ & - & - & 0.67 & - & - & 0.88 \\
\hline \multirow[t]{3}{*}{2000} & Agriculture & 7.73 & 2.56 & - & 7.66 & 2.15 & - \\
\hline & Barren & - & 88.41 & 0.48 & - & 88.63 & 0.44 \\
\hline & Built-up & - & - & 0.82 & - & - & 1.12 \\
\hline
\end{tabular}

\section{DISCUSSION}

The accuracy assessment results for the PCA based LULC images showed that the values of Kappa coefficient were $0.6667,0.6861,0.6519$ and 0.6973 for the years 1980, 1990, 2000 and 2010, respectively. However, the values for the TCT based images were $0.6978,0.7452,0.7555$ and 7524 for the years 1980, 1990, 2000 and 2010 respectively. Dymond et al. (2002) studied TCT indices for LULC studies and found that TCT can improve the accuracy of mapping and land cover classification (Table 4).

The overall accuracy of PCA based change detection was $64.58,62.68$ and $62.12 \%$ for $1980-1990,1990-2000$ and 2000-2010 images, respectively. However, the TCT based change detection resulted in higher accuracy of $77.78,75.62$ and $77.92 \%$ for $1980-1990,1990-2000$ and 2009-2010, respectively (Table 5). The results are in close agreement with the findings of Zhou et al. (2002) who obtained an overall classification accuracy of $77.8 \%$ with TCT method. However, Seto et al. (2002) obtained much higher overall accuracy of $93.5 \%$ with TCT method. Fung and Ledrew (1987) also used PCA and TCT transformed images to detect land-cover changes from multi-temporal MSS and TM images and concluded that the TCT method seems useful in many change detection applications. Rogan and Yool (2001) compared vegetation indices, PCA and TCT components and found that the TCT approach provided the best detection results of fire-induced vegetation depletion in the Peloncillo Mountains, Arizona and New Mexico, with an overall Kappa of 0.66. The improvement in the accuracy of assessment with TCT over PCA observed in this study was because the TCT transform coefficients are independent of the image scenes, while PCA is dependent on the image scenes.
Table 5. Accuracy Assessment of LULC images drawn against very high resolution images of Google Earth Database

\begin{tabular}{lllll}
\hline & $\begin{array}{l}\text { Date of } \\
\text { Mass }\end{array}$ & $\begin{array}{l}\text { Overall } \\
\text { accuracy } \\
(\%)\end{array}$ & Kappa & $\begin{array}{l}\text { Kappa } \\
\text { variance }\end{array}$ \\
\hline PCA+PCC & $14 / 9 / 1980$ & 72.00 & 0.6667 & 0.0004475 \\
& $7 / 9 / 1990$ & 78.20 & 0.6861 & 0.0005164 \\
& $2 / 9 / 2000$ & 66.10 & 0.6519 & 0.0007013 \\
& $7 / 9 / 2010$ & 58.90 & 0.6973 & 0.0007358 \\
TCT+PCC & $14 / 9 / 1980$ & 66.90 & 0.6978 & 0.0006426 \\
& $7 / 9 / 1990$ & 71.80 & 0.7452 & 0.0005911 \\
& $2 / 9 / 2000$ & 64.40 & 0.7555 & 0.0006796 \\
& $7 / 9 / 2010$ & 69.41 & 0.7524 & 0.0006897 \\
\hline
\end{tabular}

This corroborates with the finding of Almutairi and Warner (2010), who observed that PCC does not take into account the dependence existing between two images of the same area acquired at two different times. In this study, urbanized areas were particularly distinct with the high brightness pixels in the brightness component of TCT. Similarly, the biomass areas could be extracted from the brighter portions of greenness component. The results of this study are in agreement with the propositions of Jensen (2005).

In this study, the PCC method resulted in accuracies of $62-65 \%$ in PCA and $75-78 \%$ in TCT. The higher accuracies observed in TCT method could also be due to higher accuracies of classification. Serra et al. (2003) studied PCC based change detection and achieved an accuracy of $85 \%$. Yuan et al. (2005) also obtained higher accuracies of 80 to $90 \%$ with the PCC method. The results suggested that significant land use changes occurred in Dirab area from 1980 to 2010, may be related to rapid development of agriculture between 1980 and 2000 and economic development and urban expansion between 2000 and 2010. It was further noted 
that most changes occurred in cropland areas due to urban encroachment.

\section{CONCLUSION}

Land use mapping provided detailed information for assessing land use dynamics. Results of the study indicated differences in accuracies between the PCA and TCT based change detection methods. The overall accuracy of PCA based change detection was 64.58, 62.68 and $62.12 \%$ for $1980-1990,1990-2000$ and $2000-$ 2010 images, respectively. However, the TCT based change detection resulted in higher accuracy of 77.78 , 75.62 and $77.92 \%$ for $1980-1990,1990-2000$ and 2009 2010, respectively. TCT based change detection method was found to be more accurate than the PCA approach.

\section{ACKNOWLEDGEMENT}

The researchers are gratefully acknowledged the Research Chairs Programme of King Saud University, Riyah for its extended support to this research work.

\section{REFERENCES}

Al-Gaadi, K.A., M.S. Samdani and V.C. Patil, 2011. Assessment of temporal land cover changes in Saudi Arabia using remotely sensed data. Middle-East J. Sci. Res., 9: 711-717.

Al-Harbi, K.M., 2010. Monitoring of agricultural area trend in Tabuk region-Saudi Arabia using Landsat TM and SPOT data. Egypt. J. Remote Sens. Space Sci., 13: 37-42. DOI: 10.1016/j.ejrs.2010.07.005

Almutairi, A. and T.A. Warner, 2010. Change detection accuracy and image properties: A study using simulated data. Remote Sens., 2: 1508-1529. DOI: 10.3390/rs2061508

Al-Rowili, M.S., E.H. Fadda and R.A. Vaughan, 2003. A Comparison of Data Fusion and Unsupervised Classification for Change Detection in Jeddah, Saudi Arabia. In: Geoinformation for European-wide Integration, Benes, (Ed.), Millpress, Rotterdam, ISBN-10: 9077017712, pp: 259-264.

Al-Washe, M.A. and A.Y. Bokhari, 1993. Monitoring vegetation changes in Al-Madinah, Saudi Arabia, using thematic mapper data. Int. J. Remote Sens., 2: 191-197. DOI: 10.1080/01431169308904331

Bagour, M.H., S. Al-Mahlafe, A. Jacob and A. Fahsi, 2006. Change detection of the vegetation cover based upon Advanced Very High Resolution Radiometer (AVHRR) data. Res. J. Agric. Biol. Sci., 2: 341-348.
Berberoglu, S. and A. Akin, 2009. Assessing different remote sensing techniques to detect land use/cover changes in the eastern Mediterranean. Int. J. Applied Earth Observat. Geoinform., 11: 46-53. DOI: 10.1016/j.jag.2008.06.002

Bernardini, A., E.S. Malinverni, P. Zingaretti and A. Mancini, 2008. Automatic classification methods of high-resolution satellite images: The principal component analysis applied to the sample training set. Int. Arch. Photogrammetry Remote Sens. Spatial Inform. Sci., 37: 701-706.

Carr, J.R. and K. Matanawi, 1999. Correspondence analysis for principal components transformation of multispectral and hyperspectral digital images. Photogrammetric Eng. Remote Sens., 65: 909-914.

Chander, G. and B.L. Markham, 2003. Revised landsat-5 TM radiometric calibration procedures and postcalibration dynamic ranges. IEEE Trans. Geosci. Remote Sens., 41: 2674-2677. DOI: 10.1109/TGRS.2003.818464

Crist, E.P., 1985. A TM tasseled cap equivalent transformation for reflectance factor data. Remote Sens. Environ., 17: 301-306. DOI: 10.1016/00344257(85)90102-6

Currit, N., 2005. Development of a remotely sensed, historical land-cover change data base for rural Chihuahua, Mexico. Int. J. Applied Earth Obs. Geoinf., 7: 232-247. DOI: 10.1016/j.jag.2005.05.001

Daniel, L.C., J.D. Hurd, E.H. Wilson, M. Song and Z. Zhang, 2002. A comparison of land use and land cover change detection methods. Proceedings of the ASPRS-ACSM Annual Conference and FIG XXII Congress, Apr. 22-26.

Deng, J.S., K. Wang, Y.H. Deng and G.J. Qi, 2008. PCA-based land-use change detection and analysis using multitemporal and multisensor satellite data. Int. J. Remote Sens., 29: 4823-4838. DOI: 10.1080/01431160801950162

Dymond, C.C., D.J. Mladenoff and V.C. Radeloff, 2002. Phenological differences in tasseled cap indices improve deciduous forest classification. Remote Sens. Environ., 80: 460-472. DOI: 10.1016/S00344257(01)00324-8

Eastman, J.R. and M. Fulk, 1993. Long sequence time series evaluation using standardized principal components. Photogrammetric Eng. Remote Sens., 59: 1307-1312.

Fung, T. and E. Ledrew, 1987. Application of principal components analysis to change detection. Photogrammetric Eng. Remote Sens., 53: 1649-1658. 
Fung, T. and Q. Zhang, 1989. Land Use Change Detection and Identification with Landsat Digital Data. In: The Kitchener-Waterloo Area, Bryand, C.R., E.F. LeDrew, C. Marois and F. Cavayas (Eds.), Remote Sensing And Methodologies of Land Use Change Analysis, University of Waterloo, Waterloo, Ontario, Canada, pp: 135-153.

Han, T., M.A. Wulder, J.C. White, N.C. Coops and M.F. Alvarez et al., 2007. An efficient protocol to process Landsat images for change detection with tasseled cap transformation. IEEE Trans. Geosci. Remote Sens. Lett., 4: 147-151. DOI: 10.1109/LGRS.2006.887066

Hereher, M.E., A.M. Al-Shammari and S.E. Abd-Allah, 2012. Land cover classification of Hail-Saudi Arabia using remote sensing. Int. J. Geosci., 3: 349-356. DOI: 10.4236/ijg.2012.32038

Horne, J.H., 2003. A Tasseled cap transformation for ikonos images. Proceedings of the ASPRS Annual Conference, (AC' 03), Alaska, USA.

Huang, C., B. Wylie, L. Yang, C. Homer and G. Zylstra, 2002. Derivation of a tasselled cap transformation based on Landsat 7 at-satellite reflectance. Int. J. Remote Sens., 23: 1741-1748. DOI: 10.1080/01431160110106113

Jaiswal, R.K., R. Saxena and S. Mukherjee, 1999. Application of remote sensing technology for land use/land cover change analysis. J. Ind. Soc. Remote Sens., 27: 123-128. DOI: 10.1007/BF02990808

Jensen, J.R., 2005. Introductory Digital Image Processing: A Remote Sensing Perspective. 3rd Edn., Prentice Hall, Upper Saddle River, ISBN-10: 0131453610, pp: 526.

Kauth, R.J. and G.S. Thomas, 1976. The tasseled cap-a graphic description of the spectral-temporal development of agricultural crops as seen in Landsat. Proceedings of the Symposium Machine Processing Remotely Sensed Data, West Lafayette, Indiana, Jun. 29-Jul. 1, pp: 41-51.

Licciardi, G., P.R. Marpu, J. Chanussot and J.A. Benediktsson, 2012. Linear versus nonlinear PCA for the classification of hyperspectral data based on the extended morphological profiles. IEEE Trans. Geosci. Remote Sens. Lett., 9: 447-451. DOI: 10.1109/LGRS.2011.2172185.

Lillesand, T. and R. Kiefer, 2000. Remote Sensing and Image Interpretation. 4th Edn., John Wiley and Sons, Inc., Singapore.
Liu, Q. and G. Liu, 2010. Combining tasseled cap transformation with support vector machine to classify landsat tm imagery data. Proceeding of the 6th International Conference Natural Computation, Aug. 10-12, IEEE Xplore Press, Yantai, Shandong, China, pp: 3570-3572. DOI: 10.1109/ICNC.2010.5582727

Lobser, S.E. and W.B. Cohen, 2007. MODIS tasselled cap: Land cover characteristics expressed through transformed MODIS data. Int. J. Remote Sens., 28: 5079-5101. DOI: 10.1080/01431160701253303

Lu, C.H., X.B. Li and M.H. Tan, 2003. China's farmland changed and trend: A scenarios analysis. Econ. Trans. Sustain. Agric Dev. East Asia Int.

Lu, D., P. Mausel, E. Brondízio and E. Moran, 2004. Change detection techniques. Int. J. Remote Sens., 25: 2365-2401. DOI: 10.1080/0143116031000139863

Mather, P., 1999. Computer Processing of RemotelySensed Images: An Introduction. 2nd Edn., John Wiley and Sons, New York, ISBN-10: 0471985503, pp: 292.

Othman, A.A., Y.I. Al-Saady, A.K. Al-Khafaji and R. Gloaguen, 2013. Environmental change detection in the central part of Iraq using remote sensing data and GIS. Arab J. Geo Sci. DOI 10.1007/s12517013-0870-0

Petit, C., T. Scudder and E. Lambin, 2001. Quantifying processes of land-cover change by remote sensing: Resettlement and rapid land-cover changes in southeastern Zambia. Int. J. Remote Sens., 22: 34353456. DOI: 10.1080/01431160010006881

Reddy, T.B. and M.A. Gebreselassie, 2011. Analyses of land cover changes and major driving forces assessment in middle highland Tigray, Ethiopia: The case of areas around Laelay-Koraro. J. Biodiversity Environ. Sci., 1: 22-29.

Rogan, J. and S.R. Yool, 2001. Mapping fire-induced vegetation depletion in the Peloncillo Mountains, Arizona and New Mexico. Int. J. Remote Sens., 22: 3101-3121. DOI: 10.1080/01431160152558279

Serra, P., X. Ponss and D. Sauri, 2003. Postclassification change detection with data from different sensors: Some accuracy considerations. Int. J. Remote Sens., 24: 3311-3340. DOI: 10.1080/0143116021000021189

Seto, K.C., C.E. Woodcock, C. Song, X. Huang and J. Lu et al., 2002. Monitoring land-use change in the Pearl River Delta using Landsat TM. Int. J. Remote Sens., 23: 1985-2004. DOI: $10.1080 / 01431160110075532$ 
Sheng, L., J. Huang and X. Tang, 2011. A tasseled cap transformation for CBERS-02B CCD data. J. Zhejiang Univ. Sci. Biomed. Biotechnol., 12: 780786. DOI: $10.1631 /$ jzus.B1100088

Singh, A., 1989. Digital change detection techniques using remotely sensed data. Int. J. Remote Sens., 10: 989-1003. DOI: 10.1080/01431168908903939

Tahir, M., E. Imam and H. Tahir, 2013. Evaluation of land use/land cover changes in Mekelle City, Ethiopia using Remote Sensing and GIS. Comput. Ecol. Software, 3: 9-16.
Yuan, F., M.E. Bauer, N.J. Heinert and G.R. Holden, 2005. Multi-level land cover mapping of the Twin Cities (Minnesota) metropolitan area with multiseasonal Landsat TM/ETM+data. Geocarto. Int., 20: 5-14. DOI: 10.1080/10106040508542340

Zhou, S., R. Wang, M.X. Huang and D. Landgraf, 2002. Detection of coastal saline land uses with multitemporal Landsat images in Shangyu city, China. Environ. Manage., 30: 142-150. DOI: 10.1007/s00267-001-2645-8 